\title{
Experimental Investigations on the Effect of Reinforcement Coating on Magnesium Composites for Automotive Brake Pad
}

\author{
S. Venugopal $\mathbb{D},{ }^{1}$ L. Karikalan $\mathbb{D}^{1},{ }^{1}$ and R. Kumar $\mathbb{D}^{2}$ \\ ${ }^{1}$ Department of Automobile Engineering, VISTAS, Chennai 600117, India \\ ${ }^{2}$ Department of Mechanical Engineering, Eritrea Institute of Technology, Asmara 12676, Eritrea \\ Correspondence should be addressed to L. Karikalan; karilk1972@gmail.com and R. Kumar; mepcokumar@gmail.com
}

Received 10 December 2021; Accepted 15 January 2022; Published 18 February 2022

Academic Editor: Abílio De Jesus

Copyright (C) 2022 S. Venugopal et al. This is an open access article distributed under the Creative Commons Attribution License, which permits unrestricted use, distribution, and reproduction in any medium, provided the original work is properly cited.

The braking system is an important component in the automobile sector for transportation. To stop or slow down the vehicle safely, the friction brakes are employed by converting the kinetic energy to heat energy by friction. The interaction of surface materials such as rotor and pad produces heat due to friction and those materials should have a thermally stable tendency to deal with the heat than wear resistance. In this study, for the first time, an attempt is made to check the possibilities of introducing the $\mathrm{Mg}$ composite into brake pad applications. The inorganic type friction materials with various components of materials are constantly growing to get the high-performance and low-cost brake pad for commercial vehicles. The Mg composite is reinforced with electroless Ni-P-coated alumina and silicon carbide microparticles using the parameter optimized stir-squeeze method. The particles are coated by using the electroless method and various $\mathrm{Mg}$ composites such as $\mathrm{Mg}$ alloy, $\mathrm{Mg}+$ coated $\mathrm{Al}_{2} \mathrm{O}_{3}, \mathrm{Mg}+$ coated $\mathrm{Al}_{2} \mathrm{O}_{3}, \mathrm{Mg}+$ coated $\mathrm{Al}_{2} \mathrm{O}_{3}$, and $\mathrm{SiC}$ are prepared. The tribological properties of the newly formulated magnesium composite are premeditated using a tribometer. The brake pad ( $\mathrm{Mg}$ composite) material is used as a pin, and the disc material (stainless steel) is used as a plate for the experiments. Characterization of the composites is done using a FESEM machine with the attachment of EDAX to measure the elements present in the composite. The results revealed that porosity reduced significantly for the composite which has coated reinforcements. The hardness and compression strength of the composite are also enhanced for the composite which has coated reinforcements. The wear resistance of the prepared Mg composite is closer to other brake pad data, and thus, the material can be used as friction material for automotive brake pad applications.

\section{Introduction}

The necessity to develop new materials for engineering applications in the field of automotive braking systems had motivated the researcher to focus on composite materials. Composite materials can be customized based on the need for precise applications to improve properties such as resistance to tribological properties, high hardness and stiffness, and thermal, creep, and fatigue resistance [1]. Among commercially available composite materials, aluminum and magnesium are widely used for weight reduction and high performance than other materials. The commonly used reinforcement materials are $\mathrm{SiC}$ and $\mathrm{Al}_{2} \mathrm{O}_{3}$ due to their low cost and affinity with the matrix material. The effective way of fabricating the MMCs is the stir-squeeze process [2]. The interfacial adhesion between the solid and liquid phase is an important parameter during the fabrication process. The bonding strength may be reduced owing to many factors such as unwanted chemical reactions, insufficient wettability, and degradation of the particles because of high temperature. To improve the interfacial complications, several attempts are made by the researchers. Chandrasekar and Nagaraju improved the interfacial strength between the aluminum matrix and reinforcements $\mathrm{SiC}$ and $\mathrm{Al}_{2} \mathrm{O}_{3}$. They reported that the porosity strength and bonding properties are improved through electroless Ni-P coating [3]. The control parameters are required to optimize for the best product in the squeeze casting process and it was done by the earlier researcher Ramanathan et al. [4]. Thus, the optimized parameters required for the casting process were acquired. 
An alternative method to improve the interfacial bonding in the treatment of reinforcement particles before the casting process was proposed. After the successful selection of matrix material for the composite, suitable pretreatment is done on the reinforcement for the enhancement of interface properties. Urena et. al. [5] reported that a $\mathrm{SiO}_{2}$ layer was formed on the $\mathrm{SiC}$ particle surface and then the coated particle was incorporated in a molten aluminum metal; as a result, the composites show better interface property, strength, and wettability. The electroless coating is not new to the brake pad applications because in 1990 Mallory and Hajdu [6] reported the electroless application as a disc brake; however, the coating was made over the brake pad material, not on the reinforcement. The significance of the work is as follows: (a) the reinforcement coating was made on the reinforcement particles for brake pad applications; (b) for the first time, the waste magnesium AZ91 alloy material is used as a matrix for reducing the cost of the final product; and (c) also, the magnesium composite with coated reinforcement is developed for the first time to check the suitability for the brake pad applications in automobile applications. The key problem in electroless coating is the decomposition of electrolytes especially for the coating of powder materials. Arunachalam et. al. used a hybrid approach to optimize the process parameters using Taguchi grey and analytical hierarchy process techniques. From this study, the porosity is reduced to $14 \%$ and compression strength was improved by $18 \%$ [7]. Kennedy et al. investigated the aluminum composite added with titanium carbide and titanium boride microparticles with various weight percentages; as a result, the grain structure of the composite is refined at a few locations observed in the morphological analysis which improves the mechanical properties of the produced composites [8,9]. Kennedy et al. [8] developed a coating on the $\mathrm{TiC}$ microceramic particles using the reactive synthesis method in the composite material and also the presence of air bubbles/porosity in the materials is significantly reduced. Some of the earlier researchers studied the interfacial bonding and phase formation between the solid and liquid phase play an important role in improving the properties of the composite $[4,10]$. Fan et al. [11] studied the coating properties of electroless $\mathrm{Ni}$ coating on the $\mathrm{ZrO}_{2}$ particles under an SEM micrograph and they observed the uniform coating. Another research evidenced that the $\mathrm{Ni}$ coating on the $\mathrm{SiC}$ reinforcement reduces the porosity in the composite and improved the wettability and resistance to corrosion [12]. The reinforcement particles are coated with copper to enhance the interfacial bonding which boosted the bonding and mechanical properties of the composite [13]. Several investigations reported that the $\mathrm{Ni}$ coating on the reinforcement exhibits better results than $\mathrm{Cu}$ coating [14]. Thus, the electroless Ni-P coating is integrated into this work for enhancing the physical and tribological properties.

In this work, the investigations are made on the outcome of the effect of electroless Ni-P coating on the microsized reinforcements such as $\mathrm{SiC}$ and $\mathrm{Al}_{2} \mathrm{O}_{3}$ on the interfacial reaction between the matrix and reinforcement. The substrates are fabricated with several compositions such as uncoated and electroless $\mathrm{Ni}$-P-coated particles of silicon carbide and alumina. The substrates prepared are $\mathrm{Mg}$ alloy, $\mathrm{Mg}+$ coated $\mathrm{Al}_{2} \mathrm{O}_{3}, \mathrm{Mg}+$ coated $\mathrm{Al}_{2} \mathrm{O}_{3}, \mathrm{Mg}+$ coated $\mathrm{Al}_{2} \mathrm{O}_{3}$, and $\mathrm{SiC}$ using the squeeze casting process. From the developed magnesium composites, the samples are taken using the wire-cut electric discharge machining process and tested for porosity using the volume loss method, hardness values were obtained using the Rockwell hardness machine, compression strength was tested using the universal testing machine, and wear resistance and friction were determined using tribometer (pin-on-disc method). The investigations on the morphology and elemental analysis are made on the samples.

\section{Experimental Details and Procedures}

2.1. Selection of Matrix Material. The AZ91 magnesium alloy is used in high-end model cars for weight reduction, and once the car is dismantled, those components become waste and stored in stock for a long time. Those materials are available in the market for a cheaper price than new materials. In most of automobile and aerospace applications, the AZ91 alloy is widely used. After collecting the material, it is soaked and cleaned using soap oil to remove the moisture, grease, oil, and dirt and then allowed to dry. The bigger size material is reduced to the size to enter inside the electric furnace using a power hacksaw machine and portable cutting wheel machine. To confirm the composition of the collected material, a handheld XRF spectrometer is used from which the following elements are available in various percentages using RIGAKU WDXR as shown in Table 1.

2.2. Surface Preparation of Reinforcement Using Electroless $\mathrm{Ni}$ $P$ Coating. The high-purity microsized particles of size 65 and 90 microns were purchased from Sigma-Aldrich, respectively. The coating process should be carried out before the pretreatment of powder particles. The activation of the surface is essential to attract the $\mathrm{Ni}$ and $\mathrm{P}$ on it. Initially, the powder is cleaned with acetone for $10 \mathrm{~min}$. Then the powder is coarsened using the mixture of chemicals $\mathrm{HF}$ and $\mathrm{NaF}$ for $10 \mathrm{~min}$. Sensitization is done for $15 \mathrm{~min}$ using $\mathrm{SnCl}_{2}$ and $\mathrm{HCl}$. Finally, the surface of the powder is activated using $\mathrm{PdCl}_{2}$ and $\mathrm{HCl}$ mixture and doped into the solution for $15 \mathrm{~min}$. Every step should proceed after rinsing the powder with demineralized water several times. After the pretreatment process, the ceramic powder reinforcement is preserved in the electric muffle furnace at $90^{\circ} \mathrm{C}$ to eliminate the humidity in the coated particles. After the pretreatment process, the prepared particles are deposited in the chemical bath prepared for the coating process. The composition of the chemical bath is presented in Table 2 .

During the process, hydrogen bubbles get evolved and reduce the level of $\mathrm{pH}$ in the electrolyte. To neutralize this effect, the required amount of liquid ammonia is added to maintain the $\mathrm{pH}$ of $8 \pm 0.2$ in the electrolyte. The minimum spell required for the coating process is 15 minutes and the temperature is $50 \pm 2^{\circ} \mathrm{C}$. To evade the breakdown of the chemical reaction, the time for particles in the bath should be limited to 15 minutes. The reinforcement in the electroless 
TABLE 1: Element identification of the collected sample using an XRF spectrometer.

\begin{tabular}{lccccccc}
\hline Elements & $\mathrm{Mg}$ & $\mathrm{Al}$ & $\mathrm{Zn}$ & $\mathrm{Mn}$ & $\mathrm{Si}$ & $\mathrm{Cu}$ & Others \\
\hline$\%$ & 90.1 & 8.4 & 1.2 & 0.25 & 0.1 & 0.03 & 0.02 \\
\hline
\end{tabular}

TABLE 2: Chemicals required for electrolyte preparation.

\begin{tabular}{lcc}
\hline Description & Chemicals & Quantity \\
\hline Source of nickel & $\mathrm{NiSO}_{4}\left(\mathrm{H}_{2} \mathrm{O}\right)_{6}$ & $25 \mathrm{~g} / \mathrm{L}$ \\
Reducing agent & $\mathrm{NaPO}_{2} \mathrm{H}_{2} \cdot \mathrm{H}_{2} \mathrm{O}$ & $27.5 \mathrm{~g} / \mathrm{L}$ \\
Buffering agent & $\mathrm{Na}_{3} \mathrm{C}_{6} \mathrm{H}_{5} \mathrm{O}_{7}$ & $46 \mathrm{~g} / \mathrm{L}$ \\
Surface agent & $\mathrm{H}_{3} \mathrm{BO}_{3}$ & $26 \mathrm{~g} / \mathrm{L}$ \\
\hline
\end{tabular}

bath is uniformly maintained in the ratio of $0.5 \mathrm{~g} / 100 \mathrm{~mL}$ in each coating process. The moisture content in the coated particles should be removed by using an electrical muffle furnace for the duration of 2 hours at $90^{\circ} \mathrm{C}$.

\subsection{Fabrication Procedures for Stir-Squeeze Casting.} Initially, the machine is cleaned by removing the dirt and dust using a high-speed blower and then the lubrication is applied in all the places where the molten aluminum is going to flow to avoid the bonding on the surface of the machine and the machine components. Four important heating components are available in the squeeze casting machine: (1) crucible, (2) reinforcement preheating chamber, (3) die heating, and (4) runway tube heating. The above heating elements are switched on to maintain the temperature of $850,300,250$, and $300^{\circ} \mathrm{C}$, respectively. The cylindrical-shaped split die is used for the production of casting and the dimension of the die is $50 \mathrm{~mm}$ diameter and $250 \mathrm{~mm}$ height. Once the temperature is reached, it is maintained for 2 hours, and then the prepared magnesium alloy and coated/uncoated particles are charged into the furnace and pretreatment chamber to maintain the temperature. The aluminum molten metal is maintained for 1 hour in the furnace, and then, the reinforcement is preheated and added slowly by opening the valve of the reinforcement preheating chamber. The stainless steel stirrer is used to blend the coated and uncoated particles in the aluminum molten metal at the speed of $600 \mathrm{rpm}$ for 5 minutes. The stirrer is moved up and down to avoid the agglomeration of the particles. The waste materials, slag, and dirt are suspended at the top of molten metal, they can be removed manually by a scoop, and then the molten metal is allowed to pour into the slip die through the preheated runway. Instantaneously, a squeeze rod is allowed to apply the pressure of $100 \mathrm{MPa}$ for 45 seconds before solidification. The substrates are allowed to cool in the die and removed after 2 hours. Throughout the process, argon inert gas is supplied inside the crucible at the pressure of $10 \mathrm{MPa}$ to avoid unwanted reactions. From each substrate, the samples are taken at required dimensions for the testing and analysis using the wire-cut electric discharge machining process.

2.4. Characterization and Testing of Samples. The developed samples from the substrates are mounted on a BUEHLER
Automet 250, and a polishing machine is used to polish the surface of the sample using 400,600 , and 1200 grit abrasive paper. The manual polishing is done for $5 \mathrm{~min}$ with three stages of diamond suspension using a grinding machine. Keller's reagent is applied as per ASTM E3 standard on the surface of the sample as an etchant. The porosities in the surface of the samples are analyzed using KEYENCE optical microscope 1000x VHZ100R. The morphological and elemental compositions of the samples were studied using a ZEISS EVO 18SEM machine with EDX attachment. The properties of the samples are tested using a Brinell hardness machine, a universal testing machine, and a wear testing machine. Universal Hardness Tester UH-250 is used to take the hardness values at 5 different places in each sample, and the average is reported as Brinell Hardness Number (BHN). The load $500 \mathrm{~kg}$ is applied at a point for $10 \mathrm{sec}$, and then, the hardness reading is measured. A compressive force of $100 \mathrm{kN}$ is applied on the sample size of $20 \mathrm{~mm}$ height and $13 \mathrm{~mm}$ diameter using a universal testing machine at the transfer rate of $10 \mathrm{~mm} / \mathrm{min}$. A pin-on-disc tribometer (model: TR-20-PHM600, DUCOM Instruments) was used with a sliding speed of $1 \mathrm{~m} / \mathrm{s}$, a load of $35 \mathrm{~N}$, and a sliding distance of $1000 \mathrm{~m}$. The prepared sample dimension is $30 \mathrm{~mm}$ in height and $8 \mathrm{~mm}$ in diameter. A high carbon, high chromium steel is used for the analysis as a counterpart. Specific wear rate $(W)$ of the samples is calculated using the following formula:

$$
W=\frac{\Delta V}{N \times d},
$$

where $N$ is the load applied in Newton, $\Delta V$ is the volume loss in $\mathrm{mm}^{3}$, and $d$ is the sliding distance in $m$. The coefficient of friction is calculated using the following formula:

$$
\mu=\frac{F}{N},
$$

where $\mu$ is the coefficient of friction, $N$ is the applied load (in Newton), and $F$ is the friction force (in Newton). The results obtained were compared to each other through the graphical representation discussed in the next section.

\section{Results and Discussions}

Figure 1 depicts the uncoated and electroless Ni-P-coated ceramic particles such as $\mathrm{SiC}$ and $\mathrm{Al}_{2} \mathrm{O}_{3}$. The surface masking on the ceramic particles noticeably depicts the surface of the particles covered with electroless Ni-P coating. The uncoated $\mathrm{SiC}$ particles are granular in shape and are of uniform size and geometry. The alumina particles are not in granular shape and the flake geometry is observed. The coated particles are shown in Figures 1(b) and $1(\mathrm{~d})$, and it is witnessed that the Ni-P particles are bonded around the surface of the $\mathrm{SiC}$ and $\mathrm{Al}_{2} \mathrm{O}_{3}$ particles, and in few places, Ni-P alone is agglomerated. The surface of the particles concealed the total surface of the ceramic particles. Ranfang Zuo et al. studied the silver coating effects on the ash and developed the composite materials to get better properties, which is a considerably similar kind of research. 

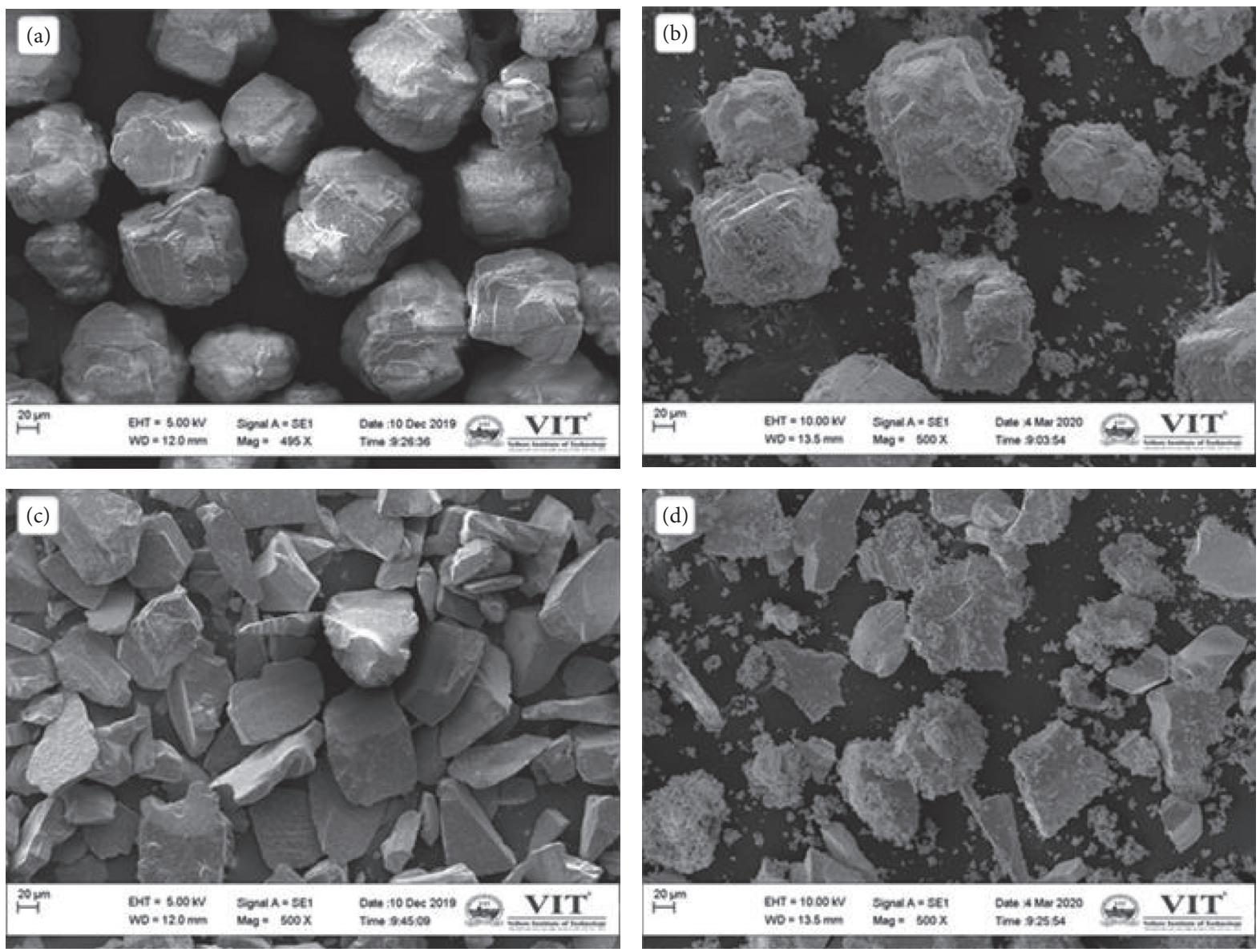

Figure 1: Surface morphology of coated and uncoated particles. (a) Uncoated $\mathrm{Al}_{2} \mathrm{O}_{3}$. (b) Coated $\mathrm{Al}_{2} \mathrm{O}_{3}$. (c) Uncoated SiC. (d) Coated SiC.

In the study of Kretz et al., the surface of the microsized $\mathrm{SiC}$ ceramic particles was covered using an electroless coating process and it has been observed that $\mathrm{Ni}$ particles are not effectively covered the surface of the particle [15]. In this work, the parameters of the electroless coating are optimized by trial and error and improved the coating on ceramic particles. The percentage of porosity for the samples is measured and shown in Figure 2. The magnesium alloy developed using the squeeze casting process has a porosity of $12.8 \%$. After the introduction of coated alumina particles, the percentage of porosity is significantly reduced to $7.5 \%$. Similarly when the coated $\mathrm{SiC}$ particles have doped the composite, the porosity is further reduced to $5.5 \%$. However, when the coated alumina and silicon carbide both are clubbed together and introduced into the molten metal, it produces a percentage porosity of $9.5 \%$. As evident, the porosity level in the composite surface is very low for the samples which have coated $\mathrm{SiC}$ and $\mathrm{Al}_{2} \mathrm{O}_{3}$ because the major problem in the $\mathrm{Mg}$ composite is the progress of porosity due to chemical reaction between the matrix and reinforcement. Few researchers reported that the porosity level in the composite is up to $40 \%$, but in this project, the maximum and minimum percentages of porosity are $12.8 \%$ and $5.5 \%$, respectively [16]. The $\mathrm{Mg}$ alloy samples show more pores on the surface as shown in the optical micrograph study. The possible reason for the high pores in the sample is due to

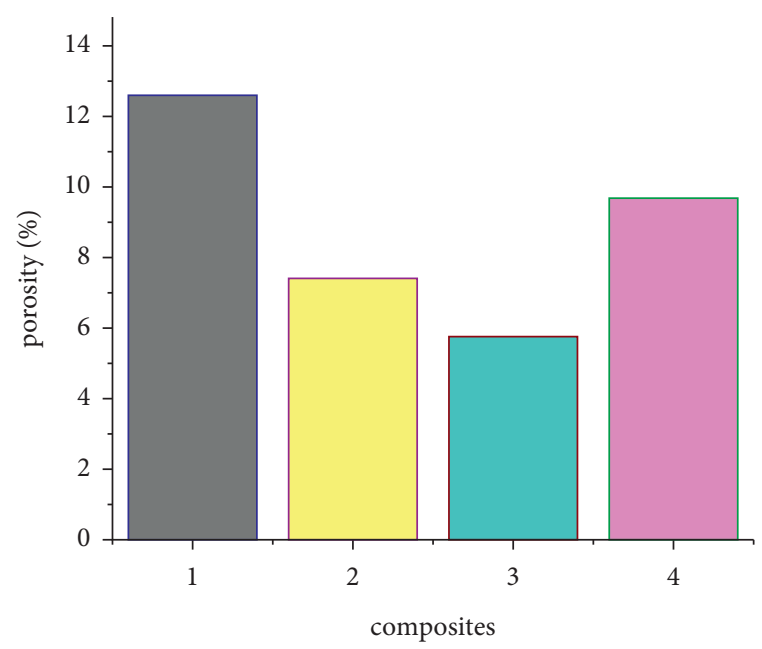

Figure 2: Percentage of porosity for the developed composites.

improper wetting which is dazed by coating. A similar experimental analysis reported that the coating improves the wetting and the particles are distributed uniformly throughout the composite; thus, the strength is improved significantly [15].

Figure 3 illustrates the optical micrograph of newly formulated magnesium composite materials. The optical 

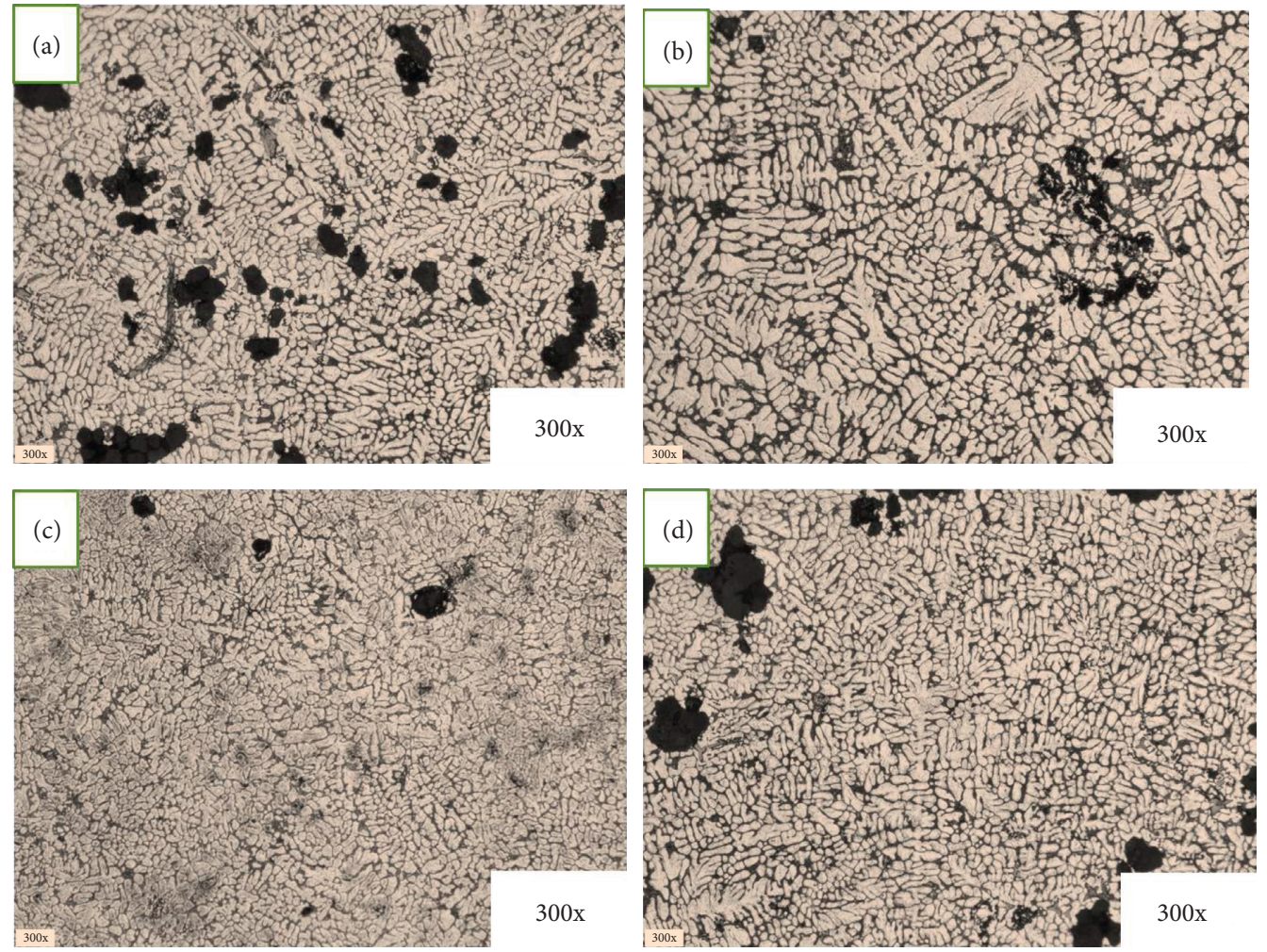

Figure 3: Optical morphological analysis of samples. (a) $\mathrm{Mg}$ alloy. (b) Coated $\mathrm{Al}_{2} \mathrm{O}_{3}$. (c) Coated SiC. (d) Coated $\mathrm{Al}_{2} \mathrm{O}_{3}+\mathrm{SiC}$.

micrograph supports the values obtained from the porosity reading obtained from the experiment. The magnesium alloy sample shows more pores on the surface of the material. However, the coated reinforcement doped composite materials have only very few pores compared to the unreinforced sample. The hybrid composite shows better results than alloy, but single ceramic coated material produces more positive results. The possible reason could be the masking of particles using Ni metal through the electroless Ni-P coating process to avoid unwanted reactions at the interface. A similar study is reported for aluminum composite that the addition of coated reinforcement reduces the porosity level in the composite [3].

Also, the coating promotes the uniform distribution of ceramic particles in the composites [17]. The SEM micrograph and EDX diffractogram of the developed magnesium composite surface are shown in Figure 4 . The group of coated materials in the composite is observed at the boundaries of the magnesium uniformly. Similar to the observation in our work, the cluster of coated $\mathrm{SiC}$ particles is shown at the boundaries of the matrix material in aluminum composite [18]. The elements present in the composites are identified and given in weight percentage. The major portion available in the composite is magnesium in all the substrates. The traces of $\mathrm{Ni}$ and $\mathrm{P}$ are available in the coated particle reinforced substrate.

The Brinell hardness values of the composites are shown in Figure 5. The magnesium alloy and hybrid composite show less hardness value when compared to the composite which has coated reinforcement. The maximum hardness value of $94 \mathrm{HRB}$ is obtained for the composite which has coated $\mathrm{SiC}$ as reinforcement. Comparable data are found in the literature also for magnesium composite with metallic glass reinforcements [19]. Cylindrical samples with dimensions of $25 \mathrm{~mm}$ length and $13 \mathrm{~mm}$ diameter were prepared for compression testing as per ASTM E9-09. The load was applied gradually at a $1.0 \mathrm{~mm} / \mathrm{min}$ crosshead speed. From the stress-strain curve, compressive strength was taken out. The compression strength value is obtained from the prepared sample from the developed substrate as shown in Figure 6. The maximum compression strength is attained for the substrate, which is electroless coated with Ni-P on silicon carbide ceramic microsized particles. The fusion of electroless coated $\mathrm{SiC}$ particles with magnesium enriches the compression strength to $320 \mathrm{MPa}$ due to the absence of pores that existed in the composite. The improvement in wetting is due to the applied coating on the reinforcement substrates. Also, the magnesium matrix controls the actions of coated particles during a distortion and makes $(\mathrm{Mg}+$ coated $\mathrm{SiC})$ harder $\mathrm{Mg}$ material than other composites [20]. According to the literature survey, the addition of microsized particles in the ductile material is the main cause for the strengthening of the composite material [21].

The compression stress-strain graph of the produced composite is shown in Figure 7. The strength of the composite is improved due to the grain refinement liquid phase, uniform distribution of hard particles, dislocation generation, and level of porosity in the composite. From the obtained results, it clearly depicts that the porosity is the main factor affecting the strength of the material [22]. The similar 

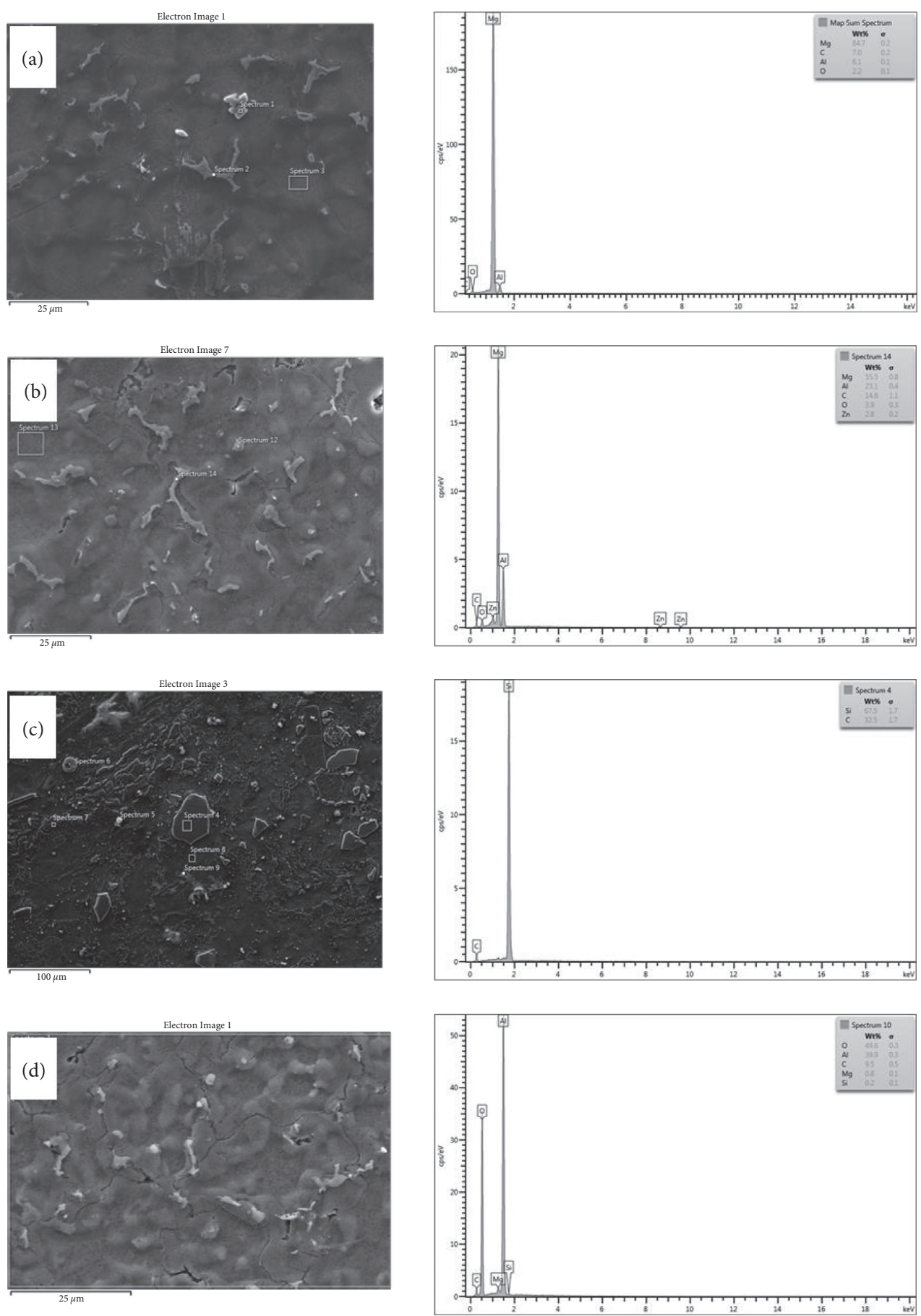

Figure 4: SEM morphological analysis and EDX analysis of samples. (a) Mg alloy. (b) Coated $\mathrm{Al}_{2} \mathrm{O}_{3}$. (c) Coated SiC. (d) Coated $\mathrm{Al}_{2} \mathrm{O}_{3}+\mathrm{SiC}$.

data reported by the earlier researcher indicate that the readings are obtained without any error [23]. The pin samples are prepared from the substrates, and the weight difference from the pin-on-disc method wear testing is measured. The specific wear rate is measured and illustrated in Figure 8. The specific wear rate is reduced for the composite, which has coated ceramic particles as reinforcement. Comparatively, the $\mathrm{SiC}$ particles are stronger than alumina and the resistance to wear is also high in the case of magnesium composite that has $\mathrm{SiC}$ as reinforcement.
In addition, the wear resistance depends on the available quantity of the composite material.

Figure 9 shows the coefficient of friction of composite material developed using the squeeze casting process. The higher COF value is obtained for the samples in the composite because the tribological film is formed between the pin material and the disc material at the interface. In common, when the applied load is increased, the COF gets increased, and thus, the load and the COF values are directly proportional. 


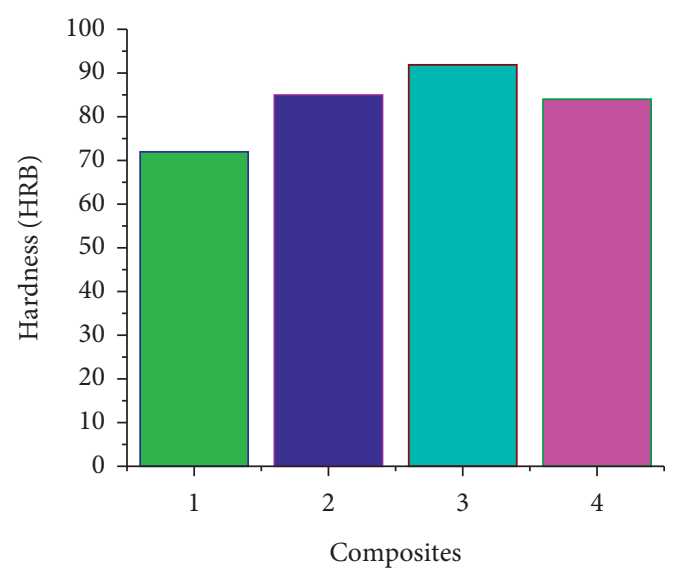

Figure 5: Hardness of various composites. (1) Mg alloy, (2) coated $\mathrm{Al}_{2} \mathrm{O}_{3}$, (3) coated $\mathrm{SiC}$, and (4) coated $\mathrm{Al}_{2} \mathrm{O}_{3}+\mathrm{SiC}$.

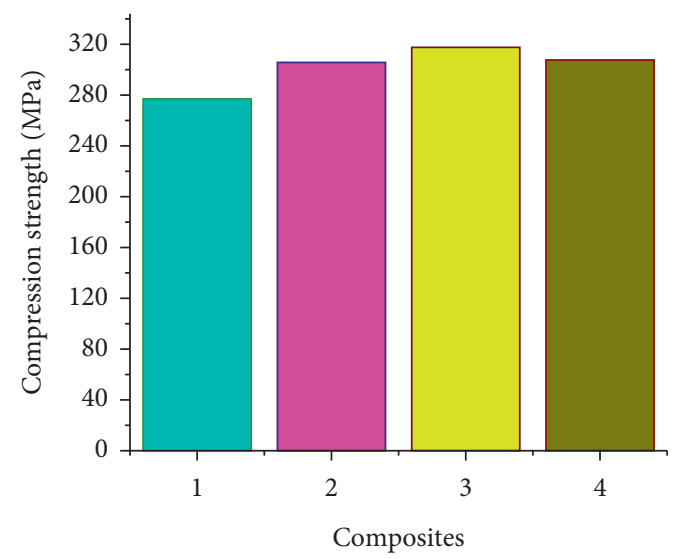

FIgURE 6: Compression strength of the developed composites. (1) $\mathrm{Mg}$ alloy; (2) coated $\mathrm{Al}_{2} \mathrm{O}_{3}$; (3) coated SiC; (4) coated $\mathrm{Al}_{2} \mathrm{O}_{3}+\mathrm{SiC}$.

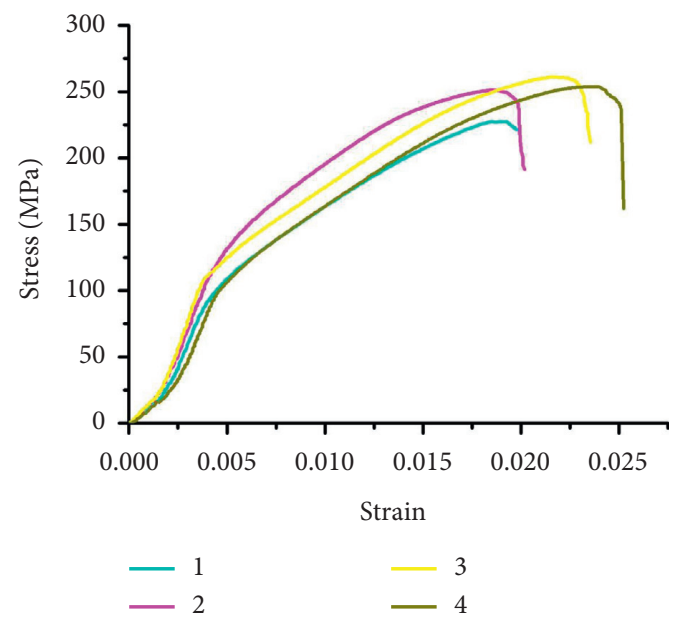

FIgURE 7: Stress-strain curve of the developed composites. (1) $\mathrm{Mg}$ alloy; (2) coated $\mathrm{Al}_{2} \mathrm{O}_{3}$; (3) coated SiC; (4) coated $\mathrm{Al}_{2} \mathrm{O}_{3}+\mathrm{SiC}$.

Related interpretations are already made by other earlier research works [24]. Archard's equation explicates the relation between the hardness of the material and its wear resistance. The wear resistance of the composite material

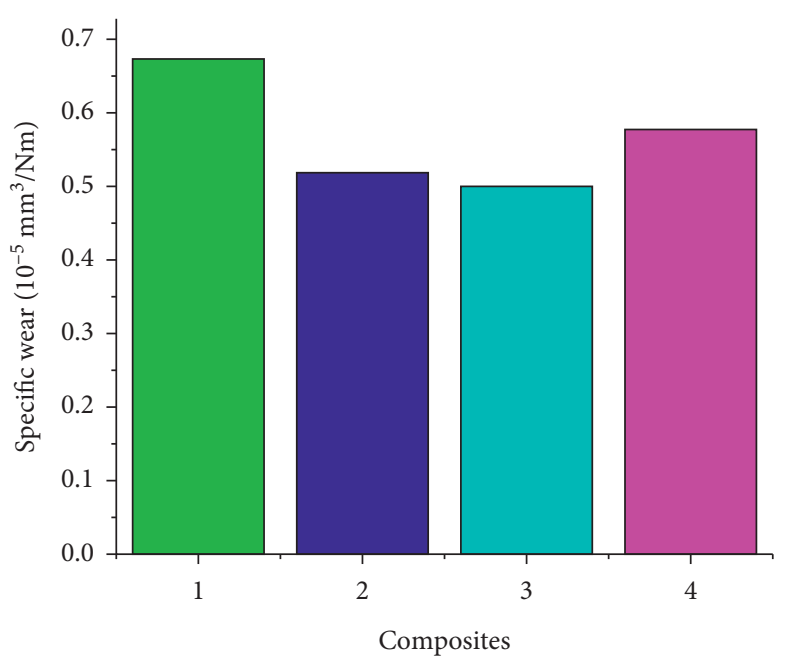

FIgURe 8: Specific wear rate of the developed composites. (1) $\mathrm{Mg}$ alloy; (2) coated $\mathrm{Al}_{2} \mathrm{O}_{3}$; (3) coated $\mathrm{SiC}$; (4) coated $\mathrm{Al}_{2} \mathrm{O}_{3}+\mathrm{SiC}$.

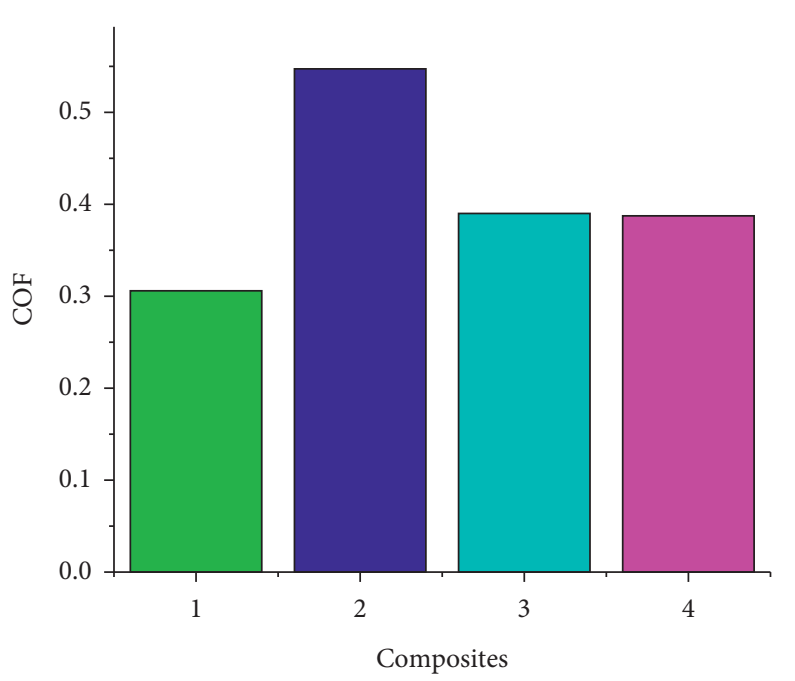

FIgURE 9: The coefficient of friction of the developed composites. (1) $\mathrm{Mg}$ alloy; (2) coated $\mathrm{Al}_{2} \mathrm{O}_{3}$; (3) coated $\mathrm{SiC}$; (4) coated $\mathrm{Al}_{2} \mathrm{O}_{3}+\mathrm{SiC}$.

could be endorsed because of the existence of tougher particles on the surface of the wear track and more resistance is formed [25].

\section{Conclusions}

The newly formulated magnesium composites with various compositions are made productively using the inert atmosphere stir-squeeze casting process. The best results of the composite are compared with the base alloy. The following conclusions are drawn based on the obtained testing and analysis:

(1) The interface bonding between the matrix and reinforcement enhanced by the metal $\mathrm{Ni}-\mathrm{P}$ coating on the surface of $\mathrm{SiC}$ and $\mathrm{Al}_{2} \mathrm{O}_{3}$ particles is clearly shown in the SEM micrograph and successfully obtained the coating on the particles. 
(2) The porosity is reduced to $55 \%$ compared to magnesium alloy without reinforcement which is also clearly depicted in the optical micrograph of various composites.

(3) The Brinell hardness value of the composite is improved to $27 \%$ and the compression strength of the material is increased to $13 \%$ than the magnesium alloy.

(4) The wear resistance of the composite is improved by $27 \%$ and the COF is improved $25 \%$ compared to the magnesium alloy.

\section{Data Availability}

The data used to support the findings of this study are included in the article. Should further data or information be required, these are available from the corresponding author upon request.

\section{Conflicts of Interest}

The authors declare that they have no conflicts of interest.

\section{References}

[1] T. P. D. Rajan, R. M. Pillai, and B. C. Pai, "Reinforcement coatings and interfaces in aluminium metal matrix composites," Journal of Materials Science, vol. 33, no. 14, pp. 3491-3503, 1998.

[2] R. Muraliraja, R. Arunachalam, I. Al-fori, M. Al-maharbi, and S. Piya, "Development of alumina reinforced aluminum metal matrix composite with enhanced compressive strength through squeeze casting process," Proceedings of the Institution of Mechanical Engineers-Part L: Journal of Materials: Design and Applications, vol. 233, Article ID 146442071880951, 2018.

[3] P. Chandrasekar and D. Nagaraju, "Improvement of bonding strength at the interfaces in scrap $\mathrm{Al}$ alloy composites using electroless Ni-P coated SiC," Silicon, 2021.

[4] A. Ramanathan, P. K. Krishnan, and R. Muraliraja, "A review on the production of metal matrix composites through stir casting - furnace design, properties, challenges, and research opportunities," Journal of Manufacturing Processes, vol. 42, pp. 213-245, 2019.

[5] A. Ureña, E. Martínez, P. Rodrigo, and L. Gil, "Oxidation treatments for $\mathrm{SiC}$ particles used as reinforcement in aluminium matrix composites," Composites Science and Technology, vol. 64, no. 12, pp. 1843-1854, 2004.

[6] G. H. Mallory, Electroless Plating-Fundamentals \& Applications, Cambridge University Press, Cambridge, London, 1990.

[7] R. Arunachalam, S. Piya, P. K. Krishnan et al., "Optimization of stir-squeeze casting parameters for production of metal matrix composites using a hybrid analytical hierarchy process-taguchi-grey approach," Engineering Optimization, vol. 52, no. 7, pp. 1166-1183, 2020.

[8] A. R. Kennedy, A. E. Karantzalis, and S. M. Wyatt, "The microstructure and mechanical properties of $\mathrm{TiC}$ and $\mathrm{TiB} 2-$ reinforced cast metal matrix composites," Journal of Materials Science, vol. 34, no. 5, pp. 933-940, 1999.

[9] A. S. Praveen and A. Arjunan, "Effect of nano- $\mathrm{Al}_{2} \mathrm{O}_{3}$ addition on the microstructure and erosion wear of HVOF sprayed
NiCrSiB coatings," Materials Research Express, vol. 7, no. 1, Article ID 015006, 2019.

[10] R. Muraliraja, R. Elansezhian, J. Sudagar, and A. V. Raviprakash, "Influence of a zwitterionic surfactant on the surface properties of electroless Ni-P coating on mild steel," Journal of Surfactants and Detergents, vol. 19, no. 5, pp. 1081-1088, 2016.

[11] L. Fan, Q. Wang, P. Yang et al., "Preparation of nickel coating on ZTA particles by electroless plating," Ceramics International, vol. 44, no. 10, Article ID 11013, 2018.

[12] V. Genova, L. Paglia, F. Marra, C. Bartuli, and G. Pulci, "Pure thick nickel coating obtained by electroless plating: surface characterization and wetting properties," Surface and Coatings Technology, vol. 357, pp. 595-603, 2019.

[13] A. M. Davidson and D. Regener, "A comparison of aluminium-based metal-matrix composites reinforced with coated and uncoated particulate silicon carbide," Composites Science and Technology, vol. 60, no. 6, pp. 865-869, 2000.

[14] P. He, S. Huang, H. Wang et al., "Electroless nickel-phosphorus plating on silicon carbide particles for metal matrix composites," Ceramics International, vol. 40, no. 10, Article ID 16653, 2014.

[15] F. Kretz, Z. Gácsi, J. Kovács, and T. Pieczonka, "The electroless deposition of nickel on $\mathrm{SiC}$ particles for aluminum matrix composites," Surface and Coatings Technology, vol. 180-181, pp. 575-579, 2004.

[16] N. Zou and Q. Li, "Compressive mechanical property of porous magnesium composites reinforced by carbon nanotubes," Journal of Materials Science, vol. 51, no. 11, pp. 5232-5239, 2016.

[17] J. Zhang, J. Li, G. Tan et al., "Thin and flexible Fe-Si-B/Ni-Cu$\mathrm{P}$ metallic glass multilayer composites for efficient electromagnetic interference shielding," ACS Applied Materials \& Interfaces, vol. 9, no. 48, Article ID 42192, 2017.

[18] K. Anand Babu, P. Venkataramaiah, and S. Yerrathota, "Material selection for preparation of aluminium hybrid mmcs sciencedirect material selection for preparation of aluminium hybrid mmcs," Materials Today Proceedings, vol. 5, Article ID 12209, 2018.

[19] D. Dash, S. Samanta, and R. N. Rai, "Study on fabrication of magnesium based metal matrix composites and its improvement in mechanical and tribological properties- a review," IOP Conference Series: Materials Science and Engineering, vol. 377, Article ID 012133, 2018.

[20] M. Hossein-Zadeh, O. Mirzaee, and P. Saidi, "Structural and mechanical characterization of Al-based composite reinforced with heat treated $\mathrm{Al}_{2} \mathrm{O}_{3}$ particles," Materials and Design, vol. 54, pp. 245-250, 2014.

[21] S. A. Sajjadi, H. R. Ezatpour, and M. Torabi Parizi, "Comparison of microstructure and mechanical properties of A356 aluminum alloy $/ \mathrm{Al}_{2} \mathrm{O}_{3}$ composites fabricated by stir and compo-casting processes," Materials \& Design, vol. 34, pp. 106-111, 2012.

[22] M. Karbalaei Akbari, H. R. Baharvandi, and O. Mirzaee, "Fabrication of nano-sized $\mathrm{Al}_{2} \mathrm{O}_{3}$ reinforced casting aluminum composite focusing on preparation process of reinforcement powders and evaluation of its properties," Composites Part B: Engineering, vol. 55, pp. 426-432, 2013.

[23] Q. Li, A. Viereckl, C. A. Rottmair, and R. F. Singer, "Improved processing of carbon nanotube/magnesium alloy composites," Composites Science and Technology, vol. 69, no. 7-8, pp. 1193-1199, 2009. 
[24] S. Kundu, S. K. Das, and P. Sahoo, "Tribological behaviour of electroless Ni-P deposits under elevated temperature," Silicon, vol. 10, no. 2, pp. 329-342, 2016.

[25] A. M. Hassan, A. Alrashdan, M. T. Hayajneh, and A. T. Mayyas, "Wear behavior of Al-Mg-Cu-based composites containing SiC particles," Tribology International, vol. 42, no. 8, pp. 1230-1238, 2009. 